\title{
Biocompatibilidade e comportamento de compósitos de hidroxiapatita em falha óssea na ulna de coelhos
}

\author{
[Biocompatibility and behavior of hydroxyapatite on bone defect on rabbit's ulna] \\ C.C. Vital ${ }^{1}$, A.P.B. Borges ${ }^{2}$, C.C. Fonseca ${ }^{2}$, A.C. Tsiomis ${ }^{1}$, T.B. Carvalho ${ }^{1}$, \\ E.B. Fontes ${ }^{3}$, M.P. Sena ${ }^{1}$, G. Fófano ${ }^{1}$ \\ ${ }^{1}$ Aluno de Pós-Graduação - UFV - Viçosa, MG \\ ${ }^{2}$ Departamento de Veterinária - UFV \\ Avenida P.H. Rolfs, s/n \\ 36570-000 - Viçosa, MG \\ ${ }^{3}$ Aluna de graduação - UFV - Viçosa, MG
}

\begin{abstract}
RESUMO
Avaliaram-se os compósitos de hidroxiapatita sintética e carbono (HAC) e hidroxiapatita sintética, carbono e fosfato biácido de sódio (HACF), ambos na forma sólida, como substituto ósseo em 36 coelhos adultos. Após protocolos anestésico e cirúrgico habituais, retirou-se um fragmento de aproximadamente $2 \mathrm{~cm}$ de comprimento no terço médio da ulna esquerda. Os animais do grupo 1 receberam, em cada falha provocada, blocos de HAC e HACF, e os do grupo 2 somente HAC. Os do grupo 3 não receberam tratamento. Os animais foram submetidos a avaliações clínicas e radiológicas nos dias 8, 15, 30, 60, $120 \mathrm{e}$ 180 de pós-operatório. Nas mesmas datas, dois animais de cada grupo foram sacrificados e deles colheuse material para histologia. Observou-se evolução normal da regeneração óssea em todos os animais, sendo mais precoce nos dos grupos que receberam os compósitos. O uso de HAC e HACF na ulna de coelho mostrou-se um método eficiente, não apresentando sinais de infecção e nem evidência de rejeição.
\end{abstract}

Palavras -chave: coelho, biomaterial, hidroxiapatita, substituto ósseo

\begin{abstract}
Composites of synthetic hydroxyapatite and carbon (HAC) and synthetic hydroxyapatite, carbon and sodium biacid phosphate (HACF), both of them in solid form, as substitute in bone regeneration were studied. Thirty-six rabbits divided in three groups were used. After routine anesthetic and surgical procedure, a bone fragment with two-centimeter in length was taken from the middle part of the left ulna. Animals from group 1 received one block of $H A C$ and $H A C F$, from group 2 received only $H A C$, in the criated bone defect, and animals from group 3 did not receive any treatment. They were submitted to clinical and radiographic examinations at 8, 15, 30, 60, 120 and 180 days after surgery to evaluate bone healing. At the same dates, two animals of each group were enthanised and bone fragments were collected for histological evaluations. The results showed normal evolution of bone regeneration in all groups but faster in animals that received the composites. The use of HAC and HACF showed to be efficient and biocompatible, and not caused rejection.
\end{abstract}

Keywords: rabbit, biomaterial, hydroxyapatite, bone substitute

Recebido para publicação em 25 de junho de 2004

Aceito em 21 de setembro de 2005

* Autor para correspondência

E-mail: andrea@ufv.br 


\section{INTRODUÇÃO}

A utilização de biomateriais no reparo de partes danificadas do tecido ósseo tem revolucionado a ortopedia e a odontologia atuais. O emprego de substâncias químicas que facilitem a reparação óssea, através da osteogênese, osteoindução e osteocondução, é alvo de pesquisas constantes (Borges, 1998; Franco et al., 2001; Legeros, 2002).

Os biomateriais podem ser definidos como substâncias de origem natural ou sintética, tolerados de forma transitória ou permanente pelos diversos tecidos que constituem os órgãos dos seres vivos (Moraes, 2002). Eles devem ser inertes, degradáveis e absorvíveis e favorecerem o crescimento ósseo por condução e, se possível, por indução. Essas características dependem das propriedades físicas e químicas do material, que devem ser compatíveis com as reações fisiológicas do osso (Borges, 1998).

O grupo de biomateriais que mais se assemelham à composição do osso é o das cerâmicas de fosfato de cálcio (Legeros, 2002), dentre as quais a mais difundida é a hidroxiapatita (HAP), cuja estrutura química é representada pela fórmula $\mathrm{C}_{10}\left(\mathrm{PO}_{4}\right)_{6}(\mathrm{OH})_{2}$. A HAP, produzida sinteticamente desde o início dos anos 70, tem sido usada clinicamente desde o início dos anos 80 (Schmitz et al., 1999).

As propriedades biológicas da hidroxiapatita sintética (HAP) são bem documentadas na literatura. Ela já foi utilizada na correção de defeitos ósseos no homem e em várias espécies animais, com resultados satisfatórios o suficiente para ser indicada como alternativa para a enxertia óssea na rotina clínica (Franco et al., 2001; Legeros, 2002).

Segundo Schmitz et al. (1999), Franco et al. (2001) e Legeros (2002), a HAP é biocompatível com o osso pelo fato de possuir a mesma estrutura cristalina, sendo assim considerada como o sólido inorgânico mais importante em biologia.

A HAP é esterilizável e relativamente não absorvível (Pollick et al., 1995; Ono et al., 2000). É vantajosa por causa de sua composição uniforme, alta biocompatibilidade, segurança (não é tóxica, nem alergênica ou carcinogênica) e pelo fato de sua microestrutura (tamanho dos poros) ser completamente controlável (Ono et al., 2000).

A estrutura porosa da hidroxiapatita funciona como suporte passivo à neoformação vascular, o que leva à proliferação de fatores indutores da aposição óssea (Borges, 1998). Segundo Vidigal Jr. e Goisman (2003), a superfície porosa da hidroxiapatita parece fornecer um substrato adicional à proliferação do tecido ósseo. A hidroxiapatita permite a junção, proliferação, migração e expressão fenotípica de células ósseas, o que resulta em formação de novo osso, em aposição direta ao biomaterial (Sakano et al., 2001; Legeros, 2002).

O objetivo deste trabalho foi avaliar a eficiência da hidroxiapatita sintética associada apenas ao carbono e associada ao carbono e ao fosfato biácido de sódio no preenchimento de defeito ósseo na ulna de coelhos, pela avaliação de sua osteointegração, por meio de estudos clínicos, radiológicos e histológicos.

\section{MATERIAL E MÉTODOS}

Utilizaram-se 36 coelhos adultos, clinicamente sadios, da raça Nova Zelândia, com média de peso de $3 \mathrm{~kg}$. Os animais foram alojados em gaiolas individuais, onde receberam ração comercial uma vez ao dia e água à vontade. Antes de serem confinados nas gaiolas, receberam uma dose única de $0,2 \mathrm{ml}$ de ivermectina ${ }^{1}$.

Foram constituídos três grupos com 12 animais cada. Os do grupo 1 receberam hidroxiapatita associada ao carbono e ao fosfato biácido de sódio, os do grupo 2 receberam hidroxiapatita associada apenas ao carbono e os do 3 não receberam tratamento.

Em todos os animais, produziu-se uma falha óssea no terço médio da ulna esquerda, conforme procedimento descrito a seguir: após tricotomia e desengorduramento do membro torácico esquerdo, os animais foram sedados com acepromazina $^{2} 1 \%$, na dose de $0,2 \mathrm{ml} / \mathrm{kg}$ e anestesiados com associação de tiletamina e

\footnotetext{
${ }^{1}$ Mogimec $®$ Mogivet

${ }^{2}$ Acepram ${ }^{\circledR}$ Univet
} 
zolazepam ${ }^{3}$, na dose de $0,4 \mathrm{ml} / \mathrm{kg}$, ambos pela via intravenosa. Fez-se uma incisão na face lateral no terço médio do membro torácico esquerdo, expondo a ulna por meio de incisão longitudinal da pele e afastamento do tecido muscular, produzindo uma falha óssea de, aproximadamente, $2 \mathrm{~cm}$ em todo o seu diâmetro, com auxílio de um martelo ortopédico e um osteótomo. Introduziu-se, então, um bloco de aproximadamente $1,8 \times 1,8 \times 1,8$ de hidroxipatita associada ao carbono e ao fosfato biácido de sódio e outro de hidroxiapatita, associada ao carbono, nos animais dos grupos 1 e 2, respectivamente. No grupo 3, o defeito provocado não recebeu tratamento, sendo utilizado como controle. Os tecidos incisados foram suturados de maneira rotineira.

As avaliações clínicas e da ferida foram diárias, observando-se presença de reação inflamatória, sensibilidade à dor e deiscência da ferida. Não se utilizaram antibiótico e antiinflamatório durante o experimento. Foram realizadas radiografias dos membros operados nas posições mediolateral e craniocaudal, imediatamente após a cirurgia e aos 8, 15, 30, 60, 120 e 150 dias do pósoperatório, visando à comparação entre osso controle e osso tratado.

Para análise histológica, de dois animais de cada grupo, sacrificados com super-dosagem de tiletamina e zolazepam, desarticulou-se o membro torácico esquerdo na articulação umeroradioulnar, nas mesmas datas de realização das radiografias. Para histologia, coletou-se material, de aproximadamente $2,5 \times 2,5 \times 2,5 \mathrm{~cm}$, sobre a região do implante das hidroxiapatitas. Fragmentos de mesmas dimensões foram retirados dos animais do grupo-controle. As amostras foram fixadas em formol a 10\%, tamponado, por aproximadamente 20 dias.

Completada a fixação, as amostras foram descalcificadas em ácido fórmico a 10\%, tamponado com citrato de sódio para $\mathrm{pH} 4,5 \mathrm{sob}$ vácuo moderado, com duração média de 15 dias. A seguir, foram lavadas em água corrente, desidratadas em álcool 70, 80, 90 e 100\% por, aproximadamente, 12 horas em cada etapa, com repetição, e diafanizadas em dois banhos de xilol, por duas horas cada.

${ }^{3}$ Zoletil ${ }^{\circledR}$ Virbac
Os fragmentos foram embebidos em parafina e mantidos em estufa a $58^{\circ} \mathrm{C}$ durante uma noite e, então, incluídos em parafina. A seguir, cortes de $7 \mu \mathrm{m}$ foram obtidos em um micrótomo rotativo e montados em lâmina de vidro. De cada bloco de parafina foram obtidas, pelo menos, duas lâminas para que fossem submetidas à técnica de coloração pela hematoxilina-eosina, visando à identificação e análise histológica da amostra.

Nas seções histológicas analisaram-se o padrão de regeneração do tecido com base nos graus de proliferação e diferenciação celular no tecido cicatricial, a neoformação óssea e sua maturação, a incorporação da hidroxiapatita ao osso, a formação de medula óssea e o nível de degradação do material investigado.

Usou-se análise qualitativa descritiva e comparação entre os grupos tratados e controle.

\section{RESULTADOS E DISCUSSÃO}

Logo após a cirurgia, os animais não apoiaram o membro operado. Tanto no grupo-controle quanto nos grupos tratados, o retorno completo à função do membro ocorreu em aproximadamente sete dias, diferente dos resultados encontrados por Borges (1998), Rezende et al. (1998) e Franco et al. (2001), nos quais os animais não apresentaram nenhum grau de claudicação após o procedimento cirúrgico. A demora em apoiar o membro, provavelmente, deve-se ao tamanho do defeito ósseo, que resultou em maior trauma.

Os animais apresentaram evolução clínica normal, não se observando quaisquer sinais de infecção ou complicação. A cicatrização da ferida cirúrgica ocorreu por primeira intenção, sendo os pontos retirados no oitavo dia, sem que houvesse indícios de rejeição da hidroxiapatita. Estes resultados clínicos levam a acreditar na biocompatibilidade das hidroxiapatitas testadas, estando de acordo com Oonishi et al. (1997), Yamamoto et al. (2000), Schmitz et al. (1999) e Legeros (2002).

Após a cirurgia, nos grupos tratados, observou-se que o implante preencheu a falha óssea, sendo sua radiopacidade maior do que a do osso normal. Contudo, não diferiu, visualmente, entre os grupos. Isto pode ser explicado pela fórmula química da hidroxiapatita, que, em função de 
seus constituintes químicos, apresenta elevado número atômico (Ono et al., 2000). Portanto, a imagem radiográfica é representada por radiopacidade. Nas radiografias feitas imediatamente após a cirurgia e aos 8,15 e 30 dias do pós-operatório (Fig. 1), a radiopacidade do implante ainda foi superior à do osso normal. Ela diminui gradativamente e, aos 60 dias, já era menor que a do osso (Fig. 1). Esse aspecto, já esperado, e descrito por Borges et al. (2000),
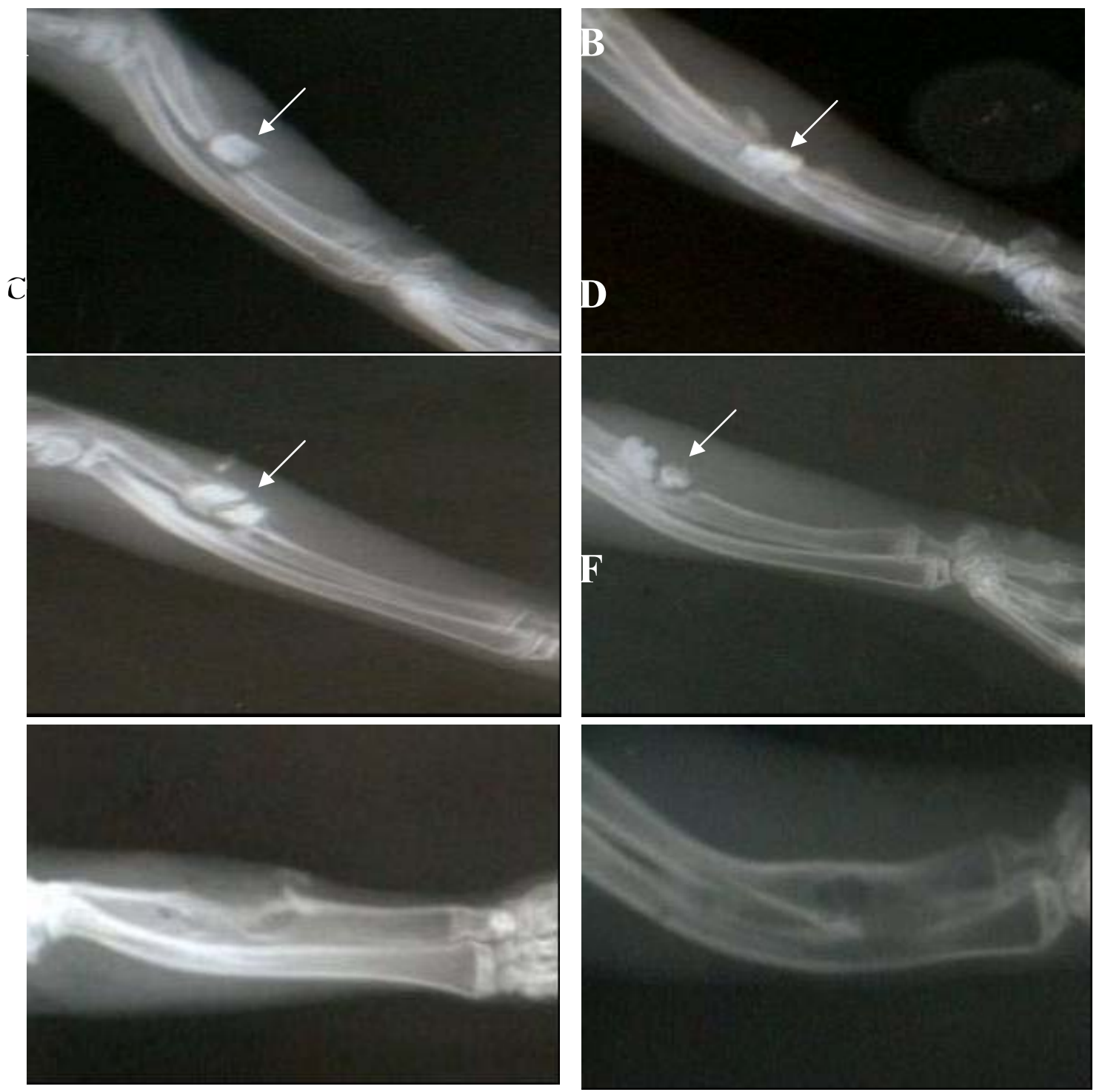

Figura 1. Radiografias de ulna de coelho tratado com hidroxiapatia (A, C, e E, grupo 1; B, D e F, grupo 2). A-oito dias após a cirurgia; B-15 dias após a cirurgia; C-30 dias após a cirurgia; D-60 dias após a cirurgia; E- 120 dias após a cirurgia; F- 120 dias após a cirurgia; seta- hidroxiapatita 
No oitavo dia, nos animais dos dois grupos tratados, não havia sinais de qualquer reação óssea. No $15^{\circ}$ dia, em todos os animais, pôde-se notar o começo de crescimento ósseo, notado pelo aumento da radiopacidade do defeito, que ocorria paralelamente à diminuição da radiopacidade da hidroxiapatita. $\mathrm{O}$ aumento de radiopacidade do defeito deve-se, provavelmente, ao começo da formação óssea que ocorreu no local. Aos 60 dias, a radiopacidade unia as extremidades da ulna, sugerindo a formação de uma ponte óssea. Em um dos animais foi observado crescimento ósseo deslocando a HAP. Aos 120 e 150 dias (Fig. 1), a hidroxiapatita ainda era visível, mas ocorreu a formação de duas corticais ósseas envolvendo o implante.
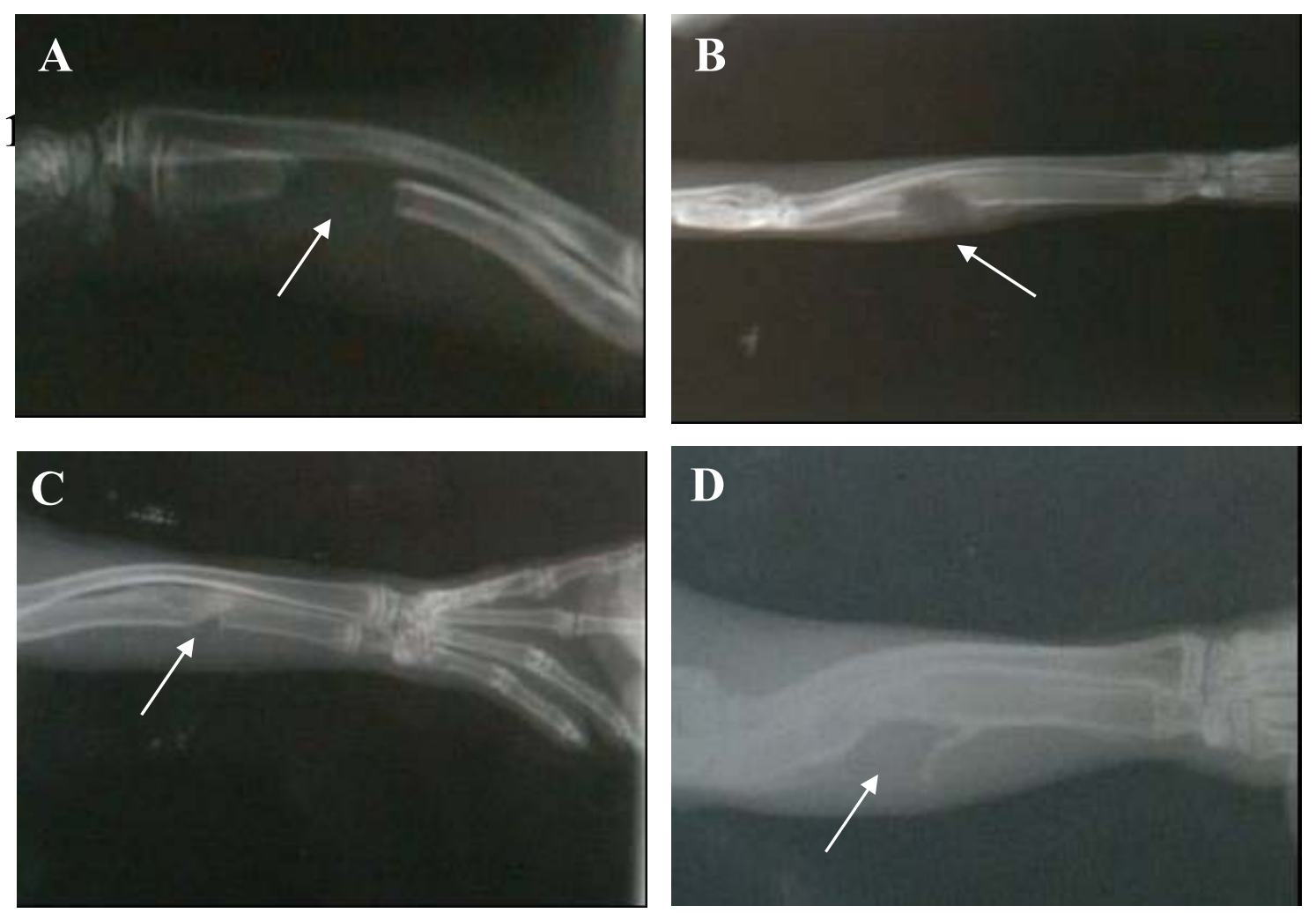

Figura 2. Radiografias de ulna de coelho do grupo-controle evidenciando o defeito ósseo (seta) produzido na ulna e sua evolução de radiopacidade. A-imediatamente após a cirurgia; B-15 dias após a cirurgia; C-30 dias após a cirurgia; D-60 dias após a cirurgia.

Aos oito dias do pós-operatório, nos animais do grupo-controle, a imagem radiográfica foi semelhante à imagem obtida imediatamente após a cirurgia, indicando que aparentemente ainda
Em apenas um animal, a massa radiopaca característica de hidroxiapatita, do grupo HAC, deslocou-se do lugar original, provavelmente por crescimento ósseo entre as extremidades fraturadas da ulna.

Nos animais do grupo-controle, após a cirurgia, foi constatada a presença de falha óssea radiotransparente (Fig. 2). Segundo Fehlberg (2001), em todo processo de reparação óssea, desenvolve-se, inicialmente, tecido conjuntivo no foco da lesão, cuja radiopacidade é insuficiente para ser perceptível ao exame radiográfico, pelo fato de os constituintes químicos do tecido neoformado serem de baixo número atômico. 
se notar radiopacidade semelhante à do osso normal, o que também foi observado por Rezende et al. (1998), Borges (1998) e Fehlberg (2001). Aos 60 dias, o defeito encontrava-se quase que em sua totalidade radiopaco como osso normal (Fig. 2). Aos 120 e 150 dias, o defeito ainda era visível, porém com a presença de uma ponte óssea. $\mathrm{O}$ defeito estava praticamente preenchido por tecido radiopaco, sugerindo a formação de tecido ósseo.

A caracterização da presença de hidroxiapatita foi evidenciada por meio de análise histológica do grupo tratado, que se apresentou sob a forma de material amorfo, acelular, bem delimitado e com maior afinidade pela hematoxilina, já descrita por Borges (1998).

Em todos os grupos, aos oito dias de pósoperatório, observou-se atividade osteoclástica nas bordas da fratura. Tal atividade sugere o início do processo de regeneração óssea, que é caracterizada pelo debridamento das bordas da lesão. Este achado é compatível com a descrição de Borges (1998), Franco (2000) e Fehlberg (2001). Percebeu-se intensa formação óssea com o esboço de cartilagem sendo substituído por tecido conjuntivo. O tecido condróide induziu a formação conjuntiva que será substituída pelo tecido ósseo (Fig. 3A e B). Foram observadas, ainda, áreas de medula óssea com ossificação intramembranosa, característico de processo de ossificação normal, como o descrito por Junqueira e Carneiro (1998), Slatter (1998), Flach et al. (2002) e Fossum (2002).

No grupo-controle, aos oito dias de pósoperatório, foram identificados osteócitos encerrados em osso trabecular (Fig. 3) e osteoblastos localizados nas bordas das trabéculas ósseas, seguindo um processo normal de reparação óssea, conforme o descrito por Flach et al (2002) (Fig. 4A). Aos 15 dias de pósoperatório, observou-se predomínio de tecido cartilaginoso desorganizado e, ainda, presença de osso trabecular bem definido (Fig. 4B). A presença de tecido cartilaginoso desorganizado pode ser explicada pelo grande tamanho do defeito provocado, levando à maior instabilidade no foco da fratura. Essa instabilidade predispõe à formação de tecido cartilaginoso conforme descreveu Flach et al. (2002).

Nos grupos com hidroxiapatita, aos 15 dias de pós-operatório, observou-se que a hidroxiapatita estava praticamente toda circunscrita por osso trabecular. Havia a presença de tecido conjuntivo desorganizado, agregados de tecido cartilaginoso na periferia da falha e intensa vascularização. Como foi descrito por Borges (1998), Borges et al. (2000) e Franco (2000), evidenciou-se grande aporte sangüíneo para a área, o que é um fator importante nos processos de reparação óssea.

Aos 30 dias de pós-operatório, os animais do grupo-controle apresentaram formação de osso novo a partir das bordas da lesão, mas com a falha óssea preenchida por tecido conjuntivo frouxo, o que, segundo Fehlberg (2001), é característico de um processo de reparação normal. Havia a presença de projeções de tecido conjuntivo denso e restos de cartilagem, e, ainda, esboço de medula óssea e predomínio de osso trabecular. Nos grupos tratados, observou-se maior formação óssea ao redor da hidroxiapatita, fato comprovado pelos resultados radiográficos. Na região da falha óssea, verificou-se a presença de osso trabecular (Fig. 3D e 3E). Aos 60 dias de pós-operatório, no grupo-controle, observou-se maior grau de substituição de tecido cartilaginoso por tecido ósseo quando comparado ao grupo de 30 dias. Porém, a formação óssea era mais evidente no grupo tratado, no qual o osso apresentava trabéculas mais espessas, tendendo a osso compacto (Fig. 3F), confirmando os achados de Oonish et al. (1997), Borges et al. (2000) e Franco et al. (2001), ao citarem a característica osteocondutora da hidroxiapatita.

Aos 120 dias de pós-operatório, os achados histológicos mostraram um tecido ósseo denso bem mais desenvolvido nos grupos tratados do que no grupo-controle. A hidroxiapatita estava bem incorporada pelo tecido ósseo, havendo ainda presença de tecido conjuntivo na falha óssea e presença de osso se organizando em fase adiantada de regeneração (Fig. 4C). 

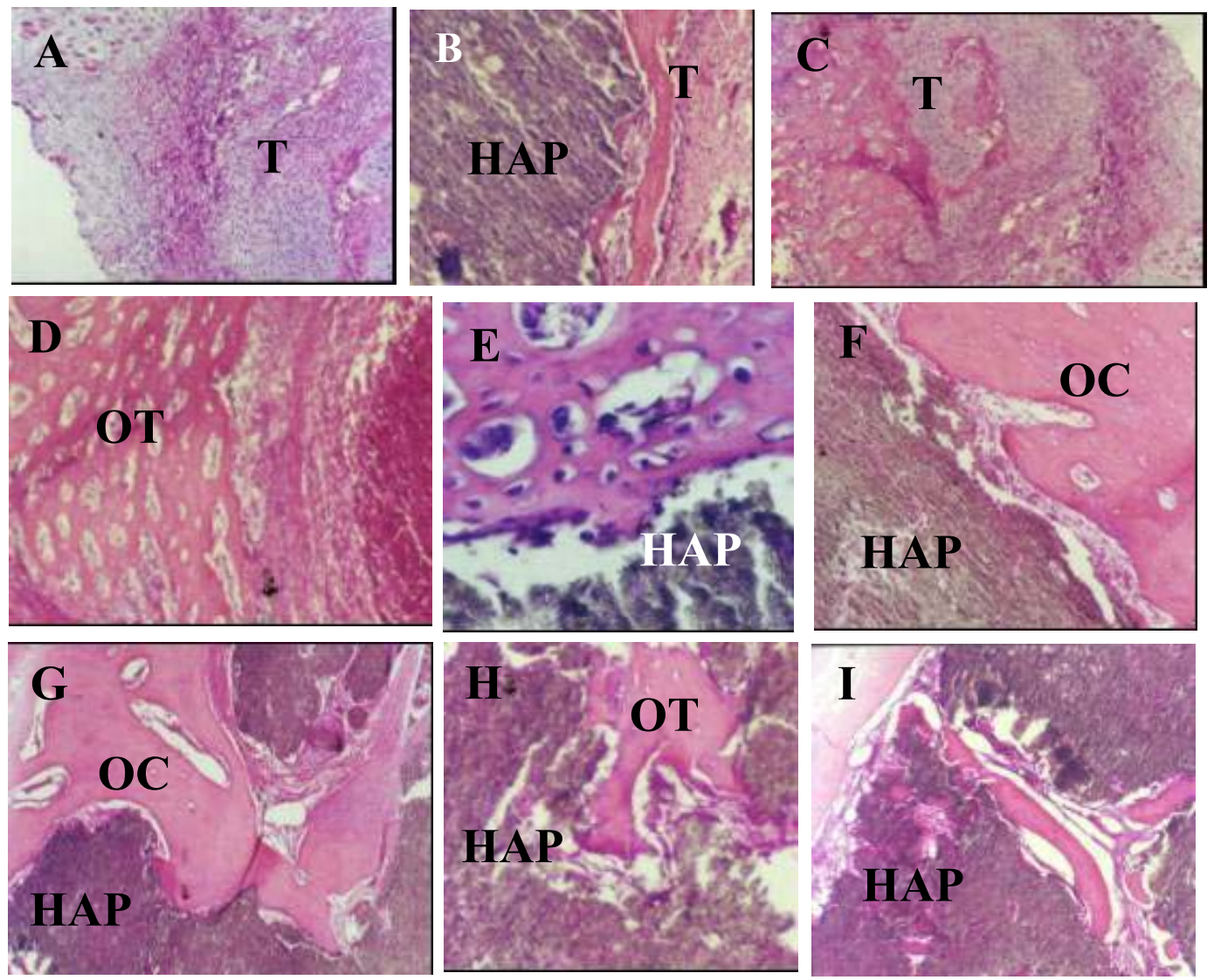

Figura 3. Fotomicrografias de ulna de coelho aos 8, 30, 60 e 120 dias após confecção de defeito ósseo e adição de hidroxiapatita (A, B, C e D, grupo 1; E, F, G, H e I, grupo 2). A- oito dias, 40×; B- oito dias, 30×; C- oito dias, 50×; D- 30 dias, 40×; E- 30 dias, 260×; F- 60 dias, 60×; G- 120 dias, 20×; H- 120 dias, $80 \times$; I- 120 dias, 40×. HE. TC: tecido cartilaginoso; OC: tecido ósseo compacto; OT: tecido ósseo trabecular; HAP: hidroxiapatita.

O processo de reparação óssea nos grupos tratados mostrou-se mais adiantado que no grupo-controle até as observações de 120 dias. A partir daí, e na observação seguinte, não houve diferença qualitativa entre os grupos. Esse fato reforça a afirmação de vários autores, como Oonish et al. (1997), Rezende et al. (1998), e Legeros (2002), os quais atribuem o efeito osteocondutor da hidroxiapatita como um favorecedor da regeneração óssea.

Aos 150 dias, tanto nos grupos tratados quanto no grupo-controle, já existia medula óssea e, praticamente, não se notava mais a presença de tecido cartilaginoso. Nos dois grupos havia tecido ósseo maduro na região da falha, mostrando processos de reparação óssea bem adiantados, o que é compatível com os resultados de Franco (2000).

Conclui-se que ambos os tipos de hidroxiapatitas usadas mostraram-se biocompatíveis, por não ter havido, em nenhum dos animais, qualquer indício de rejeição do implante ou de reação inflamatória. Nos animais tratados, o processo de regeneração óssea ocorreu mais cedo do que nos animais do grupo-controle, o que comprova a capacidade osteocondutora da hidroxiapatita. 

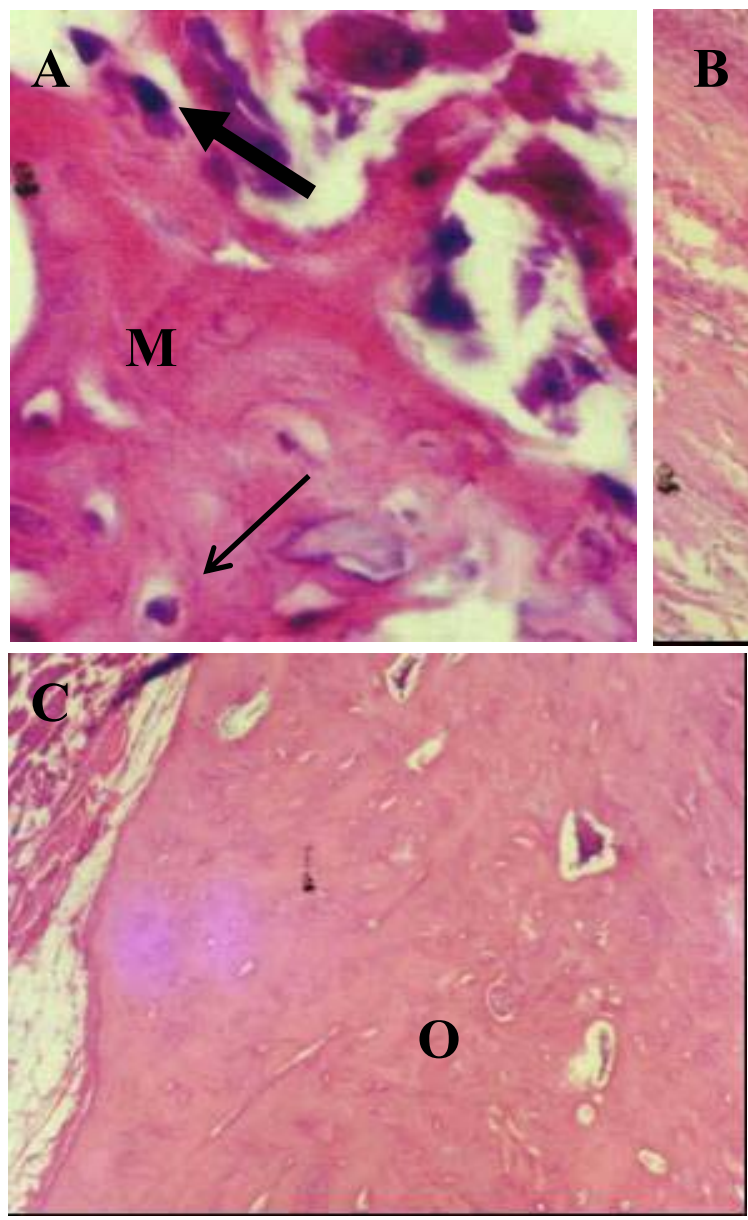
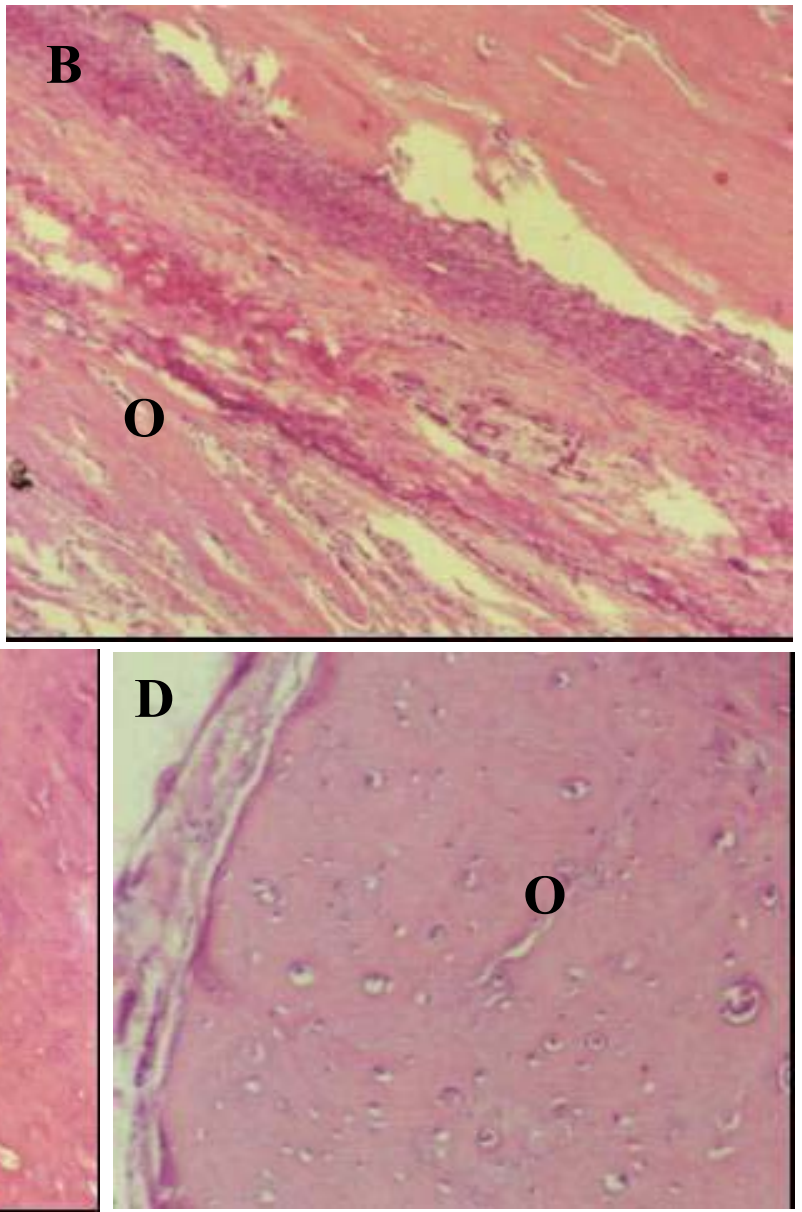

Figura 4. Fotomicrografias de ulna de coelho aos 8, 15, 120 e 150 dias após produção de defeito ósseo. A8 dias, 600×; B- 15 dias, 40×; C- 120 dias, 30×; D- 150 dias. 30×. HE. OC: tecido ósseo compacto; M: matriz óssea; OT: tecido ósseo trabecular. Seta: osteócito encerrado em lacuna; seta larga - osteoblasto.

\section{REFERÊNCIAS BIBLIOGRÁFICAS}

BORGES, A.P.B. O efeito da hidroxiapatita sintética na regeneração óssea de defeito provocado experimentalmente no terço proximal da tíbia de cães: estudo clínico-cirúrgico, radiológico e histológico por microscopia de luz e microscopia eletrônica de retrodisperção. 1998. 112f. Tese (Doutorado)- Escola de Veterinária, Universidade Federal de Minas Gerais, Belo Horizonte, MG

BORGES, A.P.B.; REZENDE, C.M.F.; RIBEIRO, M.F.B. et al. Hidroxiapatita sintética (HAP-91) como substituto ósseo em defeito experimental provocado no terço proximal da tíbia em cão: aspectos à microscopia eletrônica de transmissão. Arq. Bras. Med. Vet. Zootec., v.52, p.616-620, 2000.

FEHLBERG, A.F. Hidroxiapatita sintética na regeneração de falha óssea provocada em fratura completa de terço intermédio de tíbia imobilizada pela fixação percutânea em cães. 2001. 42f. Tese (Mestrado)- Universidade Federal de Viçosa, Viçosa, MG.

FLACH, D.M.; GORGOZINHO, K.B.; PRAZERES, M.N. et al. Regeneração óssea em cães e gatos. 2002. Disponível <http://www. uff.org.br/regeneracao-ossea.htm $>$ Acessado em 23 fev. 2003.

FOSSUM, T. Cirurgia de pequenos animais. São Paulo: Roca, 2002. p.792-797. 
FRANCO, K.L. Avaliação clínico-cirúrgica, radiológica e histológica da reparação óssea após a utilização de HAP-91, COL.HAP-91 e INT.HAP-91 em defeito provocado experimentalmente na tíbia de cães. 2000. 22f. Monografia (Especialização)- Universidade Federal de Viçosa, Viçosa, MG.

FRANCO, K.L.; BORGES, A.P.B.;VILÓRIA, M.I.V. et al. Hidroxiapatita sintética pura, hidroxiapatita associada ao colágeno e hidroxiapatita sintética associada ao lipossoma como substitutos ósseos em defeitos provocados na tíbia de cães: aspectos da osteointegração à microscopia de luz transmitida. Arq. Bras. Med. Vet. Zootec., v.53, p.431-436, 2001.

JUNQUEIRA, L.C., CARNEIRO, J. Histologia básica. 9.ed. Rio de Janeiro: Guanabara Koogan, 1994. $427 \mathrm{p}$.

LEGEROS, R.Z. Properties of osteoconductive biomaterials: calcium phosphates. Clin. Orthop. Rel. Res., v.395, p.81-98, 2002.

MORAES, P.C. Biocompatibilidade $e$ comportamento do cimento de fosfato de cálcio, reforçado com diferentes tipos de fibras, implantado no rádio de coelhos. 2002. 73f. Tese (Mestrado)- Faculdade de Ciências Agrárias e Veterinárias, Universidade Estadual Paulista, Jaboticabal, SP.

ONO, I.; TATESHITA, T.; NAKAJIMA, T. Evaluation of a high density polyethyelene fixing system for hydroxyapatite ceramic implants. Biomaterials, v.21, p.143-151, 2000.

OONISHI, H.; KUSHITANI, S.; YASUKAWA, E. et al. Particulate bioglass compared with hydroxyapatite as a bone graft substitute. Clin. Orthop. Rel. Res. v.334, p.316-325, 1997.

POLLICK, S.; SHORS, E.C.; HOLMES, R.E. et al. Bone formation and implant degradation of coralline porous ceramics placed in bone and ectopic sites. J. Oral Maxillofac. Surg., v.53, p.915-922, 1995.

REZENDE, C.M.F.; BORGES, A.P.B.; BERNIS, W.O. et al. Aspectos clínicoscirúrgicos e radiográficos da hidroxiapatita sintética na diáfise proximal da tíbia de cães. Arq. Bras. Med. Vet. Zootec., v.50, p.537-545, 1998.

SAKANO, H.; KOSHINO, T.; TAKEUCHI, R. et al. Treatment of the instable distal radius fracture with external fixation and a hydroxyapatite spacer. J. Hand Surg., v.26, p.923-929, 2001.

SCHMITZ, J.P.; HOLLINGER, J.O.; MILAM, S.B. Reconstruction of bone using calcium phosphate bone cements: a critical review. J. Oral Maxillofac. Surg., v.57, p.1122-1126, 1999.

SLATTER, D. Manual de cirurgia de pequenos animais. 2.ed. São Paulo: Manole, 1998. p.18911899.

VIDIGAL Jr., G.M.; GOISMAN, M. Osseointegração $\times$ biointegração: uma análise crítica. Rev.Bras. Odontol. V.4, p.54, 1997.

YAMAMOTO, T.; ONGA, T.; MARUI, T. et al. Use of hydroxyapatite to fill cavities after excision of benign bone tumours. J. Bone Joint Surg., v.82-B, p.1117-1120, 2000. 